\title{
INVESTIGATION OF THE TRANSFORMATION OF THE STRUCTURE AND PROPERTIES OF HEREDITY OF THERMOFRICTIONAL HARDENING OF STEEL UNDER CONDITIONS OF ELEVATED TEMPERATURES
}

\author{
${ }^{1}$ Oleh VOLKOV, ${ }^{1}$ Nikolaj POGREBNOY, ${ }^{1}$ Valeria SUBBOTINA, ${ }^{2}$ Miroslaw RUCKI, \\ ${ }^{3}$ Alexander SHELKOVOY, ${ }^{3}$ Mykola NAKONECHNY, ${ }^{3}$ Nina ZUBKOVA, ${ }^{3}$ Yuriy GUTSALENKO \\ ${ }^{1}$ National Technical University "Kharkiv Polytechnic Institute", Department of Materials Science, \\ Kharkiv, Ukraine \\ ${ }^{2}$ Kazimierz Pulaski University of Technology and Humanities in Radom, Department of Materials Science, \\ Radom, Poland, EU \\ ${ }^{3}$ National Technical University "Kharkiv Polytechnic Institute", Department of M. F. Semko Integrated \\ Engineering Technology, Kharkiv, Ukraine, yu.gutsalenko@gmail.com
}

https://doi.org/10.37904/metal.2021.4207

\begin{abstract}
Thermofriction hardening of steels is a modern technology for extended use in the production of various parts, the surfaces of which require increased wear resistance. The presented research continues the work of the authors on the study of the transformation and properties of metal structures that have received frictional processing; identification of physical mechanisms of steel hardening and the formation of ideas about residual manifestations and support of the strength heredity of intense frictional contact in the subsequent life cycle of the part at the final operations of its shaping and operation under conditions of thermophysical loading similar to tempering. This study examines the behavior of surfaces hardened by thermofrictional treatment under conditions of subsequent operational thermal loading, which is simulated by heating to elevated temperatures (up to $600{ }^{\circ} \mathrm{C}$ ) and holding steel at these temperatures for up to one and a half hours. Metallographic and durametric studies have been carried out on cross-sectional sections of $65 \mathrm{G}$ steel samples. The microhardness in the near-surface layer decreases the more, the higher the heating and the time of testing with an elevated temperature. At the same time, the surface of steel that has previously undergone thermofrictional hardening is much harder than its base in the entire range of experimental conditions. This indicates the prospects of thermofriction hardening for steel products operating under conditions of increased thermal loads, and stimulates further research in this direction.
\end{abstract}

Keywords: Metallography, dispersion, white layer, heating, microhardness

\section{INTRODUCTION}

Strengthening of materials, and especially surface hardening, is today a very popular issue, which is used for a wide range of products. The use of various approaches to surface hardening is a topical issue and is actively studied with a wide geography.

Frictional processes are a potentially powerful source of energy and are used even in processes such as welding. In the literary source [1], the influence of the parameters of this type of welding on the thermal phenomena that occur during this process is considered. In many cases, surface treatment in various ways produces white layer structures that have a certain degree of similarity. Informative, from a scientific point of view, is the study of the behavior of individual structural components during deformation of materials. Thus, the behavior of the austenitic component in alloy steel is considered during hot deformation in a scientific article [2]. 
In [3] the influence of electro-erosive treatment on the microstructure of the white layer and its corrosion resistance is considered. The work [4] is devoted to the description of the martensitic white layer, which is obtained in steel by adhesive sliding friction. Analysis of the effect of surface nanocrystallization on friction and wear resistance of low-carbon steel is considered in [5]. The nanostructured surface layer, which is formed in the materials under the action of treatment with surface mechanical friction is described in [6]. It should be noted that an important operational parameter is the size of grain the objects under study. Scientific work [7] is devoted to the influence of grain size on the wear resistance of nanostructured steel. In [8] the influence of strain hardening on the wear resistance of Gadfield steel is described.

A detailed work [9] is devoted to the microstructural evolution of the white layer in steels, but only from the standpoint of the influence of mechanical contact. The attention of [10] is also drawn to the structure and properties of the white layer as a consequence of intensive mechanical processing. Thermally deformed white layers as applied to high carbon steel are considered in [11].

The application of alternative technologies for steel products using friction processes can significantly reduce industrial costs and obtain products of high functionality. This can contribute to an increase in the economic effect, both in production and in the use of various products. In this regard [12], the use of thermo-friction hardening (TFH) is economically attractive in obtaining steel products with high hardness and, accordingly, the expected wear resistance of the surface.

In addition to the ability to quickly and inexpensively harden the surface of various objects, it is important to meet a number of requirements for them, expanding the possibilities of effective use in various conditions, including stressful operation. In this direction, the stability of the structure and properties of products at elevated temperatures is important. This study is aimed specifically at studying the behavior of the technological heredity of steel TFH under conditions of elevated temperatures, transformation of the structure and properties provided by the TFH.

\section{EXPERIMENTAL PROCEDURE}

The study was carried out on the example of steel 65G (Table 1). Among its foreign analogues, the leading countries of the steel industry are represented by many brands, in particular 1066 (USA), 66Mn4 (Germany), 080A67 (Great Britain), 65Mn (China). The choice of the steel grade for research, in addition to its well-known industrial popularity, is also due to the previous experience of experimental work with it as a material for the production of knives, using an electric current activated by the discharge action in the diamond-spark grinding zone at the end of the technological cycle of manufacturing the TFH post, while maintaining a functionally positive technological inheritance of the previous friction hardening [13]. An important aspect of expanding the use of steel knives in the context of this study is both cold and hot cutting of different materials.

Table 1 Chemical composition of steel, \% wt

\begin{tabular}{|c|c|c|c|c|c|c|c|c|}
\hline $\mathbf{C}$ & $\mathbf{S I}$ & $\mathbf{M n}$ & $\mathbf{N i}$ & $\mathbf{S}$ & $\mathbf{P}$ & $\mathbf{C r}$ & $\mathbf{C u}$ & $\mathbf{F e}$ \\
\hline $0.62-0.7$ & $0.17-0.37$ & $0.9-1.2$ & $\leq 0.25$ & $\leq 0.035$ & $\leq 0.035$ & $\leq 0.25$ & $\leq 0.2$ & Rest, $997-98$ \\
\hline
\end{tabular}

Flat specimens for research with dimensions of $100 \mathrm{~mm} \times 40 \mathrm{~mm} \times 25 \mathrm{~mm}$ were preliminarily passed through the TFH on 3G71 surface grinding machine (Figure 1) using disc tool made of St3 steel with the following processing modes: peripheral speed of the too $35 \mathrm{~m} \cdot \mathrm{s}^{-1}$, sample feed rate $30 \mathrm{~mm} \cdot \mathrm{s}^{-1}$, processing depth $0.7 \mathrm{~mm}$.

The study of the features of structural changes in steel and the assessment of the behavior of the microhardness of white layers under test conditions with an increase in temperature after TFH were carried out by heating to $200{ }^{\circ} \mathrm{C}, 400{ }^{\circ} \mathrm{C}, 600{ }^{\circ} \mathrm{C}$, and holding for $10 \mathrm{~min}$., $30 \mathrm{~min}$., $60 \mathrm{~min}$., $90 \mathrm{~min}$. at these 
temperatures. The range of heating temperatures is adopted according to the classical tempering temperatures [14].

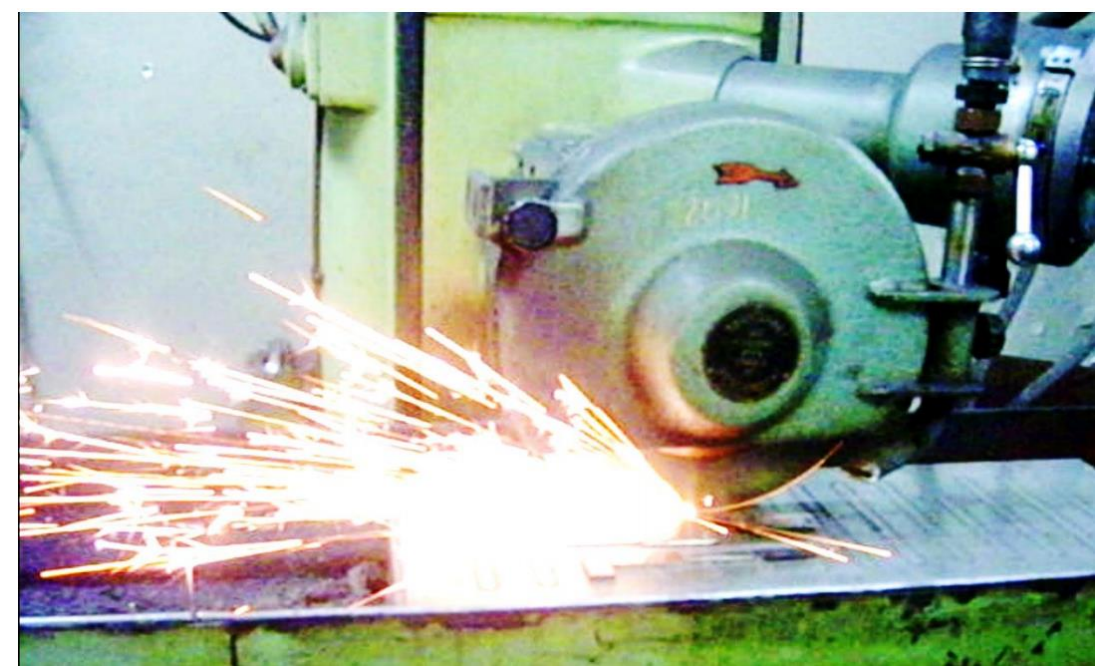

Figure $1 \mathrm{TFH}$ process

Metallographic analysis along the slice of standard etched thin sections after TFH and furnace heating was carried out using an MIM-7 microscope, by photographing microstructures together with a micrometer ruler and using interchangeable objectives and eyepieces with different optical characteristics.

The microhardness was measured using a PMT-3 microhardness tester with a load on the indenter of $100 \mathrm{~g}$. The distance between the edge of the sample and the first indentation was $3 \mu \mathrm{m}$, and between the subsequent ones $-5 \mu \mathrm{m}$ or more, depending on the homogeneity of the layers to be removed.

\section{RESULTS AND DISCUSSION}

The measured data on the microhardness of white layers after heating with different holding times are shown in (Table 2).

Table 2 Microhardness of the white layer after TFH and heating, GPa

\begin{tabular}{|c|c|c|c|}
\hline \multirow{2}{*}{ Temperature holding time, $\min }$. & \multicolumn{3}{|c|}{ Heating temperature, ${ }^{\circ} \mathbf{C}$} \\
\cline { 2 - 4 } & $\mathbf{2 0 0}$ & $\mathbf{4 0 0}$ & $\mathbf{6 0 0}$ \\
\hline 10 & 17.4 & 14.3 & 8.0 \\
\hline 30 & 16.0 & 12.0 & 6.2 \\
\hline 60 & 14.5 & 10.7 & 5.6 \\
\hline 90 & 14.0 & 10.0 & 5.0 \\
\hline
\end{tabular}

Structural changes that occur when the samples are heated after their TFH showed that there is a relative stability of the white surface layer. In all samples, after heating, three characteristic zones are preserved (hardening, thermal softening, base metal, which were considered in previous studies, with the initial microhardness of the white surface layer $18.0 \mathrm{GPa}$ [12].

When heated to a temperature of $200{ }^{\circ} \mathrm{C}$, white surface layer of the samples (hardening zone) (Figure 2a) has a fine-grained structure with an oblong grain shape and a size significantly smaller than the size of martensitic needles, which make up the base metal layer. The level of its microhardness is significantly higher than in the base metal zone of samples after preliminary quenching and low-temperature tempering. This is visually shown 
by microhardness prints in photos of microstructures. The average depth of this strengthening zone is $0.6-0.7$ $\mathrm{mm}$.

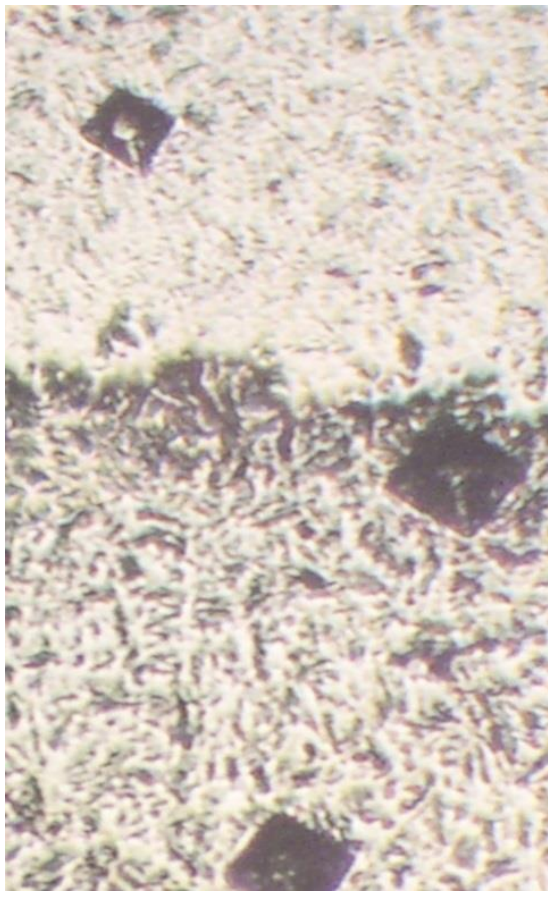

a)

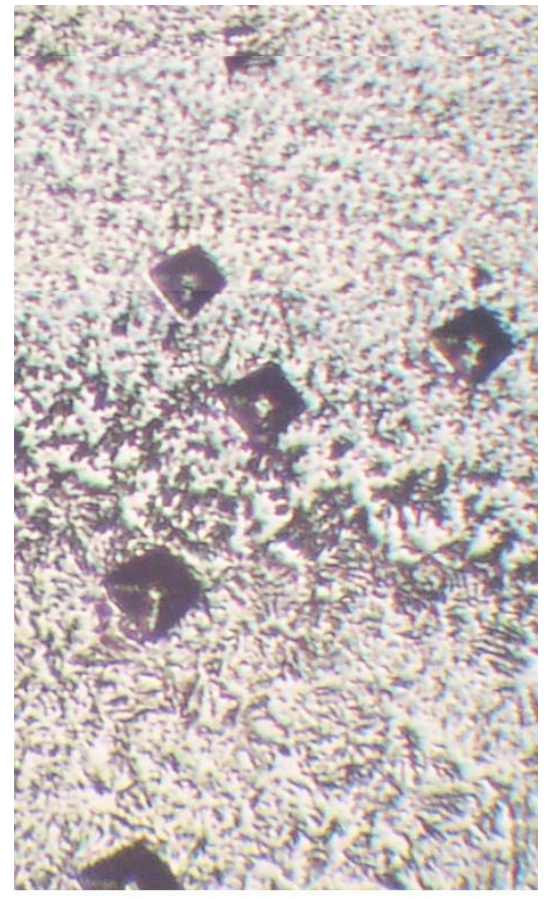

b)

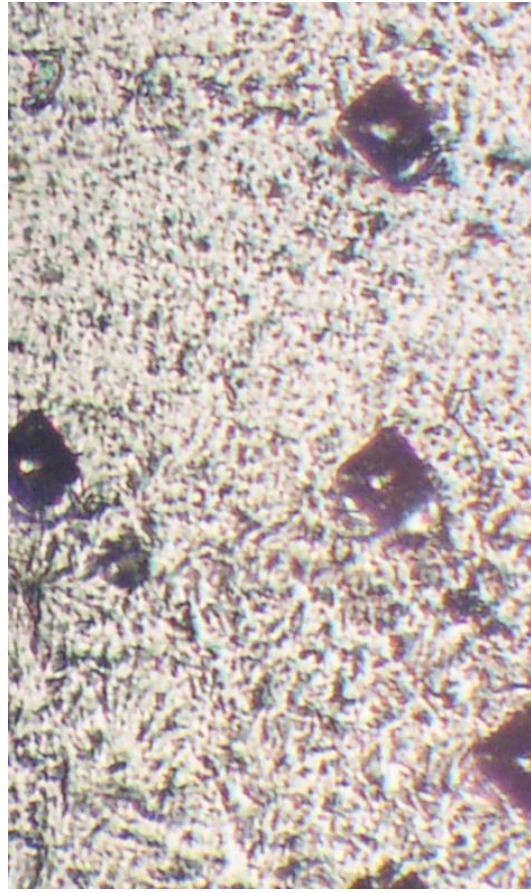

c)

Figure 2 The microstructure of the cross section after TFH, heating to temperatures of $200{ }^{\circ} \mathrm{C}(\mathrm{a}), 400^{\circ} \mathrm{C}(\mathrm{b}), 600^{\circ} \mathrm{C}(\mathrm{c})$, and holding for $30 \mathrm{~min}$. Magnification 500

The zone of base metal is shown at the bottom of microstructures photos (Figure 2). It has a needle-like structure of martensite after low-temperature tempering caused by previous heat treatment by TFH exactly in this temperature range (about $200^{\circ} \mathrm{C}$ ). Its microhardness reaches $6.5 \mathrm{GPa}$.

These two zones are connected by a rather thin layer with a darker structure of a different type, with a minimum level of hardness. The microhardness here decreases to the level of $3.5 \mathrm{GPa}$, which is typical for the thermal softening. This low level of hardness is explained by the spread of tempering temperatures to this depth, and the structures corresponds to sorbite-like - and troostite-like.

When heated to temperature $400{ }^{\circ} \mathrm{C}$, the cross-section pattern (three zones) remains, which is described above. However, there are significant changes in the hardening zone and the base metal zone. At a given temperature, these zones instead of the martensitic structure acquire the structure of troostite after mediumtemperature tempering (Figure $\mathbf{2 b}$ ).

This structure is formed as a result of the decomposition of martensite (transformation of type martensite perlite). However, the degree of dispersion of the hardening zone troostite and the base metal zone troostite is not the same and is higher in the hardening zone. This can be explained by the conditions for obtaining a surface reinforced layer at TFH. It include the deformation component and provide the appearance of more crystallization centers on which troostite grains grow (Hall - Petch).

However, in these samples, the volume of transformations occurred partially. Its completeness is directly proportional to the holding time at the specified temperature. Sample after holding for 30 minutes has a microhardness of the base metal zone of $5.2 \mathrm{GPa}$. The degree of thermal softening is more pronounced in samples where the exposure time was $60 \mathrm{~min}$ and $90 \mathrm{~min}$. The microhardness of the base metal is reduced to $4.9 \mathrm{GPa}$ and $4.5 \mathrm{GPa}$, respectively. The depth of reinforcement does not change and is $0.6-0.7 \mathrm{~mm}$. 
The study of the microstructure and microhardness samples after TFH and heating to a temperature of $600{ }^{\circ} \mathrm{C}$ and determined holding found that there is still some separation between the hardening zones and the base metal. However, the structure of these zones consists of sorbite after high-temperature tempering (Figure 2c), which also has a higher degree of dispersion in the hardening zone. This structure is also formed as a result of the decomposition of martensite (transformation of type martensite - perlite). Complete transformation occurs in the sample, where the exposure time was 90 minutes., by analogy with heating up to $400{ }^{\circ} \mathrm{C}$.

At the same time there is a drop in microhardness, both in the zone of hardening (Table 1) and in the zone of the base metal. However, the microhardness of the surface layer is higher compared to base metal, where 4.8 $\mathrm{GPa}$ at 10 minutes of holding, $4.2 \mathrm{GPa}$ at 30 minutes of holding, $3.8 \mathrm{GPa}$ at 60 minutes of holding and 3.5 $\mathrm{GPa}$ at 90 minutes of holding.

The softening zone visually disappears, as its troostite part undergoes changes similar to the base metal, and merges with it. However, the transition from the hardening zone to the base metal zone due to the different grain size in them remains noticeable. The depth of the hardening zone did not change either, and it was in the interval of $0.6-0.7 \mathrm{~mm}$.

The results obtained in this study show that at all heating temperatures, an increase in the holding time slows down the softening, and the holding time of 90 minutes practically ensures the final completeness of the transformation of the structure and properties of steel after TFH. In all cases, the microhardness indices of the hardening zone (surface layer) after testing at elevated temperatures remain higher than the microhardness of the base metal.

This fact is explained by the fact that under TFH conditions, in addition to heating, a strain-stress state is formed in the sample surface. This initiates the appearance of a large number of crystallization centers. When heated to martensite decomposition temperatures, they provoke the growth of a large number of grains of perlite-like structures (troostite and sorbite), which makes them finer-grained.

As a result, the complex of mechanical properties in general increases. It should also be noted that fine grain, first of all, contributes to an increase in impact strength [15]. This is very important in the surface layers of machine parts and tools. In addition, the depth of hardening maintains constant stability and does not change under the influence of temperature on the samples. Therefore, it is important to emphasize the possibility of effective use of TFP as a method of surface strengthening, and machine parts and tools that are strengthened in this way can work effectively, including in conditions of elevated temperatures.

\section{CONCLUSION}

The performed studies provide information on the nature and results of the transformation of the structure and properties of steel $65 \mathrm{G}$ provided by the TFH after subsequent exposure to certain elevated temperatures (200 ${ }^{\circ} \mathrm{C}, 400{ }^{\circ} \mathrm{C}, 600^{\circ} \mathrm{C}$ ) for up to $90 \mathrm{~min}$., after which the change (weakening) of the technological heredity of the TFZ can be considered relatively insignificant for operational prospects. At the same time, in the entire temperature range of tempering in steel that has passed the TFH, fine grain and increased hardness indicators are preserved. With a short holding time at specified temperatures (up to $30 \mathrm{~min}$ ), the processes of decay of the structures of the surface reinforced layer occur partially, almost with the preservation of the original hardness, at a level from $6.2 \mathrm{GPa}$ and above at $600{ }^{\circ} \mathrm{C}$ to not less than $12 \mathrm{GPa}$ and $16 \mathrm{GPa}$, respectively, at $400{ }^{\circ} \mathrm{C}$ and $200{ }^{\circ} \mathrm{C}$. The surface of steel that has previously undergone $\mathrm{TFH}$ is much harder than its base in the entire range of experimental conditions. This indicates the prospects of TFH for steel products and stimulates further research in this direction. The results obtained support the possibility of effective use of TFH as a method of surface strengthening, and machine parts and tools that are strengthened in this way in conditions of elevated temperatures. 


\section{REFERENCES}

[1] RAJAMANICKAM, N., BALUSAMY, V., MAGUDEESWARAN, G., NATARAJAN, K. Effect of process parameters on thermal history and mechanical properties of friction stir welds. Materials and Design. [online]. 2009, vol. 30, iss. 7, pp. 2726-2731. Available from: https://doi.org/10.1016/j.matdes.2008.09.035.

[2] MOMENI, A., ARABI, H., REZAEI, A., BADRI, H., ABBASI, S. Hot deformation behavior of austenite in HSLA-100 microalloyed steel. Materials Science and Engineering: A. [online]. 2011, vol. 528, iss. 4-5, pp. 2158-2163, Available from: https://doi.org/10.1016/j.msea.2010.11.062.

[3] SIDHOM, H., GHANEM, F., AMADOU, T., GONZALEZ, G., BRAHAM, C. Effect of electro discharge machining (EDM) on the AISI316L SS white layer microstructure and corrosion resistance. The International Journal of Advanced Manufacturing Technology. [online]. 2013, vol. 65, iss. 1-4, pp. 141-153. Available from: https://doi.org/10.1007/s00170-012-4156-6.

[4] SIPOS, K., LOPEZ, M., TRUCCO, M. Surface martensite white layer produced by adhesive sliding wear friction in AISI 1065 steel. Revista Latinoamericana de Metalurgia y Materiales. 2008, vol. 28, iss. 1, pp. 46-50.

[5] WANG, Z., TAO, N., LI, S., WANG, W., LIU, G., LU, J., LU, K. Effect of surface nanocrystallization on friction and wear properties in low carbon steel. Materials science and engineering: A. [online]. 2003, vol. 352, iss. 1-2, pp. 144-149. Available from: https://doi.org/10.1016/S0921-5093(02)00870-5.

[6] LU, K., LU, J. Nanostructured surface layer on metallic materials induced by surface mechanical attrition treatment. Materials science and engineering: A. [online]. 2004, vol. 375-377, pp. 38-45, Available from: https://doi.org/10.1016/j.msea.2003.10.261.

[7] ZHOU, L., LIU, G., HAN, Z., LU, K. Grain size effect on wear resistance of a nanostructured AISI52100 steel. Scripta materialia. [online]. 2008, vol. 58, iss. 6, pp. 445-448. Available from: https://doi.org/10.1016/j.scriptamat.2007.10.034.

[8] YAN, W., FANG, L., SUN, K., XU, Y. Effect of surface work hardening on wear behavior of Hadfield steel. Materials science and engineering: $A$. [online]. 2007, vol. 460-461, pp. 542-549, Available from: https://doi.org/10.1016/j.msea.2007.02.094.

[9] MASOUMI, M., LIMAB, B., TRESSIAC, G., SINATORAC, A., H. GOLDENSTEIN. Microstructure and crystallographic orientation evolutions below the superficial white layer of a used pearlitic rail. Journal of Materials Research and Technology. [online]. 2019, vol. 8, iss. 6, pp. 6275-6288. Available from: https://doi.org/10.1016/j.jmrt.2019.10.021.

[10] UMEMOTO, M., TODAKA, Y., LIM J. Change in microstructure and mechanical properties of steel components surface layer by severe plastic deformation. Tetsu-to-Hagané. [online]. 2008, vol. 94, iss. 12, pp. 616-628, Available from: https://doi.org/10.2355/tetsutohagane.94.616.

[11] HOSSEINI, S., KLEMENT, U., KAMINSKI, J. Microstructure characterization of white layer formed by hard turning and wire electric discharge machining in high carbon steel (AISI 52100). Advanced Materials Research. [online]. 2012, vol. 409 pp. 684-689, Available from: https://doi.org/10.4028/www.scientific.net/AMR.409.684.

[12] VOLKOV, O. A. Study of heat deformation influence in surface strain hardening of steel by thermofriction processing. Eastern-European Journal of Enterprise Technologies. [online]. 2016, vol. 2, iss. 5, pp. 38-44, Available from: https://doi.org/10.15587/1729-4061.2016.65458.

[13] POGREBNOY, N. A., SIZYI, Yu. A., GUTSALENKO, Yu. G., VOLKOV, O. A. Steel strengthened surface layer forming as result of thermofriction preprocessing and diamond-spark grinding. Proceedings of the $7^{\text {th }}$ International Conference "Research and Development in Mechanical Industry" (RADMI 2007). Belgrade, 2007, pp. 241-245.

[14] ZAKHAROV, B. Heat Treatment of Metals. Honolulu: University Press of the Pacific, 2002.

[15] SMITH, J. L., RUSSEL, G. M., BHATIA, S. C. Heat treatment of metals. Vol. 1. Singapore: Alkem Company (S) Pte Ltd., 2009. 